\title{
Brain levels of arginine-vasotocin and isotocin in dominant and subordinate males of a cichlid fish
}

\author{
Olinda Almeida a , Magdalena Gozdowska ${ }^{\text {b }}$, Ewa Kulczykowska ${ }^{\text {b }}$, Rui F. Oliveira a,c,* \\ a Unidade de Investigação em Eco-Etologia, ISPA-Instituto Universitário, Rua Jardim do Tabaco, 34, 1149-041 Lisboa, Portugal \\ ${ }^{\mathrm{b}}$ Genetics and Marine Biotechnology, Institute of Oceanology of the Polish Academy of Sciences, Powstanców Warszawy 55 st, 81-712 Sopot, Poland \\ c Champalimaud Neuroscience Programme, Instituto Gulbenkian de Ciência, Rua da Quinta Grande, 6, 2780-156 Oeiras, Portugal
}

\section{A R T I C L E I N F O}

\section{Article history:}

Received 8 September 2011

Revised 11 December 2011

Accepted 12 December 2011

Available online 20 December 2011

\section{Keywords:}

Fish

Tilapia

Vasotocin

AVT

Isotocin

Brain

Social status

\begin{abstract}
A B S T R A C T
The nonapeptides arginine-vasotocin (AVT) and isotocin (IT), which are the teleost homologues of argininevasopressin and oxytocin in mammals, have well established peripheral effects on osmoregulation and stress response, and central effects on social behavior. However, all studies that have looked so far into the relationship between these nonapeptides and social behavior have used indirect measures of AVT/IT activity (i.e. immunohistochemistry of AVT/IT immunoreactive neurons, or AVT/IT or their receptors mRNA expression with in situ hybridization or qPCR) and therefore direct measures of peptide levels in relation to social behavior are still lacking. Here we use a recently developed high-performance liquid chromatography analysis with fluorescence detection (HPLC-FL) method to quantify the levels of both AVT and IT in macro-dissected brain areas [i.e. olfactory bulbs, telencephalon, diencephalon, optic tectum, cerebellum, and hindbrain (= rhombencephalon minus cerebellum)] and pituitary of dominant and subordinate male cichlid fish (Oreochromis mossambicus). The pituitary shows higher levels of both peptides than any of the brain macroareas, and the olfactory bulbs have the highest AVT among all brain areas. Except for IT in the telencephalon there is a lack of correlations between central levels and pituitary peptide levels, suggesting an independent control of hypophysial and CNS nonapeptide secretion. There were also no correlations between AVT and IT levels either for each brain region or for the pituitary gland, suggesting a decoupled activity of the AVT and IT systems at the CNS level. Subordinate AVT pituitary levels are significantly higher than those of dominants, and dominant hindbrain IT levels are significantly higher than those of subordinates, suggesting a potential involvement of AVT in social stress in subordinate fish and of IT in the regulation of dominant behavior at the level of the hindbrain. Since in this species dominant males use urine to communicate social status and since AVT is known to have an antidiuretic effect, we have also investigated the effect of social status on urine storage. As predicted, dominant males stored significantly more urine than subordinates. Given these results we suggest that AVT/IT play a key role in orchestrating social phenotypes, acting both as central neuromodulators that promote behavioral plasticity and as peripheral hormones that promote integrated physiological changes.
\end{abstract}

(c) 2011 Elsevier Inc. All rights reserved.

\section{Introduction}

The nonapeptides arginine-vasotocin (AVT) and isotocin (IT), which are the teleost homologues of the mammalian arginine-vasopressin (AVP) and oxytocin (OT), have both peripheral effects on osmoregulation, cardiovascular and stress responses and central effects on the regulation of social behavior (Balment et al., 2006; Goodson and Bass, 2001; Kulczykowska, 2007). In fish these nonapeptides are produced by neurons localized in the parvocellular and magnocellular nuclei of the preoptic area, that project both to the neurohypophysis, where AVT/IT are released in the systemic circulation, and to multiple extrahypothalamic regions, namely the ventral telencephalon, the

\footnotetext{
* Corresponding author. Fax: + 351218860954.

E-mail address: ruiol@ispa.pt (R.F. Oliveira).
}

thalamus and the mesencephalon (Goodson and Bass, 2001; Goodson et al., 2003; Holmqvist and Ekstrom, 1995; Thompson and Walton, 2009). The functionality of the wide extrahypothalamic projections is confirmed by the presence of AVT/IT receptors in most brain regions, in particular the AVT V1a receptor (Hausmann et al., 1995; Kline et al., 2011; Lema, 2010; Lema et al., 2010).

Regarding the behavioral effects of nonapeptides AVT induces the expression of mating behavior in fish (e.g. Bastian et al., 2001; Carneiro et al., 2003; Pickford and Strecker, 1977; Salek et al., 2002; Semsar et al., 2001), and has effects on aggressive behavior that can be of opposite direction depending on the species. There are examples of AVT promoting (e.g. beaugregory damselfish, Stegastes leucostictus, Santangelo and Bass, 2006; multiband butterflyfish, Chaetodon multicinctus, Dewan and Tricas, 2011), decreasing (e.g. plainfin midshipman, Porichthys notatus, Goodson and Bass, 2000b; electric fish, Apteronotus leptorhynchus, Bastian et al., 2001; Amargosa 
pupfish, Cyprinodon nevadensis amargosae, Lema and Nevitt, 2004) or having inconclusive effects (bluehead wrasse, Semsar et al., 2001). The effects of IT on social behavior have been less studied than those of AVT. Central infusions of IT stimulate social approach towards conspecifics in goldfish (Carassius auratus), whereas AVT inhibits it (Thompson and Walton, 2004), and modulates social vocalizations in females and non-territorial males of the plainfin midshipman (P. notatus), whereas AVT modulates the same vocalizations in territorial males (Goodson and Bass, 2000a).

Given the effects of these neuropeptides on social behavior it is expected to find an association between different AVT/IT profiles and social phenotypes within the same species. For example, in species with alternative reproductive tactics, where two male morphs occur (bourgeois and parasitic males, sensu Taborsky, 1997) but only one of them expresses courtship behavior, there is an association between the expression of courtship behavior and forebrain AVT activity as measured by soma size or number of AVT-ir neurons or by AVT mRNA expression (for a review see Oliveira, 2006). AVT also correlates with social status in fish, but this relationship may differ depending on the AVT neuronal population. Territorial or dominant social status has been consistently associated with lower activity of parvocellular neurons and higher activity of gigantocellular neurons, as indicated either by smaller soma sizes or by smaller number of AVT-ir neurons or by lower mRNA expression (zebrafish, Danio rerio, Larson et al., 2006; African cichlid, Astatotilapia burtoni, Greenwood et al., 2008). Furthermore, in recent inter-specific studies comparing closely related butterflyfish species that differ in social organization (i.e. territoriality, level of aggressiveness, and mating system) it was found that territorial species have larger AVT-ir neurons in the POA and a higher density of AVT fibers in the telencephalon (Dewan et al., 2008), and that the density of AVT-it varicosities within the ventral nucleus of the ventral telencephalon (the teleost homologue of the mammalian lateral septum, Wullimann and Mueller, 2004), is the strongest predictor of the social system (Dewan et al., 2011).

In this respect it is relevant to point out that all studies that have looked into the relationship between nonapeptides and social phenotypes have used imunocytochemistry and/or in situ hybridization or qPCR and therefore have focused on measures of AVT-ir neuron morphology and mRNA expression and direct measures of peptide levels in different brain areas, where they are hypothesized to act as neuromodulators, in relation to social behavior are still lacking.

Here we use a recently developed high-performance liquid chromatography analysis with fluorescence detection (HPLC-FL, Gozdowska and Kulczykowska, 2004; Gozdowska et al., 2006) method to quantify the levels of both AVT and IT in different brain areas and pituitary of dominant and subordinate male cichlid fish (Oreochromis mossambicus). Since in this species dominant males use urine to communicate social status (Almeida et al., 2005; Barata et al., 2007) and since AVT is known to have an antidiuretic effect in fish by decreasing glomerular filtration rate (Amer and Brown, 1995; Balment et al., 1993), we have also tested the hypothesis that higher volumes of urine stored by dominant males are associated with lower levels of systemic AVT. Therefore, this study has the following specific aims:

1: to characterize the quantitative distribution of AVT and IT in different brain regions and in the pituitary;

2: to compare the quantitative levels of AVT and IT in the different brain regions and pituitary in males of different social status that exhibit different social behavior phenotypes;

3: to investigate if the hypophysial and extrahypothalamic levels of AVT and IT are coupled or not;

4: to assess if stress levels, as measured by circulating cortisol, are correlated with hypophysial levels of AVT;

5: to investigate the association between peripheral levels of AVT, as measured by the concentration of AVT in the pituitary, and urine storage in males of different social status.

\section{Materials and methods}

\section{Social phenotypes in Mozambique tilapia males}

The Mozambique tilapia is an African cichlid fish where two male phenotypes can be recognized (Oliveira and Almada, 1998). Dominant males form dense aggregations of breeding territories in shallow waters. They adopt a dark coloration, dig and defend spawning pits, and actively court females (Baerends and Baerends van Roon, 1950; Neil, 1964). Subordinate non-territorial males maintain a pale silver coloration similar to that of females and when courted by dominant males performed the full female sexual behavior, including following the courting male to the spawning pit, assuming a pivot position in the nest while the territorial male circles them, and performing chewing movements close to the genital papillae of the courting male (Oliveira and Almada, 1998). By adopting this female-mimicking behavior non-territorial males are able to remain inside the breeding aggregations and when spawning episodes occur they intrude in the spawning pits trying to achieve sneaking fertilizations (Oliveira and Almada, 1998). Non-territorial males can also rapidly become territorial when social opportunities appear (Oliveira and Almada, 1996a, 1996b). Females live in shoals and visit the breeding aggregations when they are ready to spawn. Spawning takes place in the pit and the female quickly takes eggs and sperm into her mouth where fertilization takes place (Baerends and Baerends van Roon, 1950; Neil, 1964). Females then leave the breeding area and mouthbrooding of eggs and fry is exclusively provided by the females (Bruton and Boltt, 1975; Fryer and Iles, 1972).

\section{Animals and housing}

The tilapia males used in this study were part of a stock held at ISPA-Instituto Universitário (Lisboa, Portugal) that is maintained in glass tanks $(120 \times 40 \times 50 \mathrm{~cm}, 240 \mathrm{~L})$ with a fine gravel substrate, in stable social groups of 4 males and 5 females per tank. Tanks are supplied with a double filtering system (sand and external biofilter, Eheim) and constant aeration. Water quality is monitored on a weekly basis for nitrites (0.2-0.5 ppm), ammonia ( $<0.5 \mathrm{ppm})$ (Pallintest kit ${ }^{\circledR}$ ) and $\mathrm{pH}$ (6.0-6.2). Fish are kept at a temperature of $26 \pm 2{ }^{\circ} \mathrm{C}$ and a 12L:12D photoperiod, and are fed with commercial cichlid floating and sinking sticks. The social status of the males on each tank is monitored on a daily basis, based on the body coloration and on the possession of a spawning pit on the substrate (Oliveira and Almada, 1996a).

\section{Experimental protocol}

Sixteen animals [ 8 dominants and 8 subordinates; body mass ( mean \pm S.E.M.): dominants $=89.6 \pm 17.4 \mathrm{~g}$, subordinates $=73.1 \pm$ $12.8 \mathrm{~g}$; $T$-test: $\mathrm{t}=0.741, \mathrm{p}=0.47]$ were collected from the stock tanks containing stable groups (i.e. groups that had been established between 5 and 8 weeks prior to sampling; typically each tank houses 2 dominant males, 2 subordinate males and 5 females), quickly anesthetised (MS-222, Pharmaq; 300-400 ppm) and blood samples were taken from the caudal vein (using $1 \mathrm{ml}$ syringes with $25 \mathrm{G}$ / $16 \mathrm{~mm}$ needles). Blood sampling always took less than 4 min since the induction of anesthesia to prevent possible effects of handling stress on sampled cortisol levels (Foo and Lam, 1993). Blood sample were centrifuged and the plasma was stored at $-20{ }^{\circ} \mathrm{C}$ until further processing. After blood sampling fish were returned to the anesthesia solution until muscular and opercular movements completely stop, after which they were sacrificed by decapitation. The brain and pituitary gland were then extracted from the cranial cavity and dissected into the following major brain areas: olfactory bulbs $(\mathrm{OB})$, telencephalon $(\mathrm{TL})$, optic tectum (TO), cerebellum (CB), hindbrain (= rhombencephalon minus cerebellum) (HB), diencephalon (DE) and pituitary gland (PT). The major brain areas were immediately frozen in dry ice and stored at $-80{ }^{\circ} \mathrm{C}$ until subsequent analysis. A second set of 16 males ( 8 
dominants and 8 subordinates) was used for the collection of urine samples. Urine was collected by gently squeezing the abdomen immediately above and anterior to the genital papilla, following the procedure described by Oliveira et al. (1996).

Animal procedures used in this study have been approved by the Portuguese Veterinary Office (Direcção Geral de Veterinária, license \# 0420/000/000/2007).

Quantification of nonapeptides by high performance liquid chromatography with fluorescence detection (HPLC-FL)

A recently described method of nonapeptide quantification using HPLC-FL (Gozdowska and Kulczykowska, 2004) that has been proven to be efficient in brain and pituitary tissue of other fish species (Gozdowska et al., 2006; Kleszczyńska et al., 2006, 2007) was used.

In brief the procedure consisted of the following. Brain samples were weighted, individually homogenized (using ultrasonic cell disruptor) in $1 \mathrm{~mL}$ distilled water, acidified with acetic acid $(10 \mu \mathrm{L})$, and placed in a boiling water bath for $3.5 \mathrm{~min}$. The extracts were then centrifuged $\left(20,000 \mathrm{~g}, 20 \mathrm{~min}, 4^{\circ} \mathrm{C}\right)$ and the supernatants were decanted and loaded into solid phase extraction (SPE) columns (Baker Bond, C18, $20 \mathrm{mg} 1 \mathrm{ml}$, pore size $60 \AA$, particle diameter $40 \mu \mathrm{m}$ ), that had been pre-conditioned with three portions of methanol followed by three portions of Millipore water (each of $1 \mathrm{~mL}$ ). The Baker SPE 12 G Column Processor (J.T. Baker, Phillipsburg, NJ, USA), a specially designed vacuum manifold capable of processing simultaneously up to 12 SPE columns, was used for solid phase extraction. To purify the samples the columns were washed successively by $1 \mathrm{~mL}$ of $5 \% \mathrm{CH}_{3} \mathrm{COOH}$, followed by $1 \mathrm{~mL}$ ultra pure water and finally by $1 \mathrm{~mL}$ of $5 \%$ methanol. The derivatization (cf. Gozdowska and Kulczykowska, 2004) was performed using $10 \mu \mathrm{L}$ NBD-F (4-fluoro-7-nitro-2,1,3-benzoxadiazole: $30 \mathrm{mg} / \mathrm{mL}$ acetonitrile) in $90 \mu \mathrm{L}$ borate buffer ( $\mathrm{pH} \mathrm{9.5)}$ for $20 \mathrm{~min}$ at room temperature. After washing by-products with $0.5 \mathrm{~mL}$ water and $0.5 \mathrm{~mL}$ methanol (10\%), the peptides were eluted with a $2 \mathrm{~mL}$ mixture of ethanol: $\mathrm{HCl}$ (2000:1). The eluate was collected, dried under air and stored at $-80^{\circ} \mathrm{C}$ until further processing.

HPLC analyses were performed with the Beckman Instruments (San Ramon, CA, USA) connected with a spectrofluorometric detector RF-551 (Shimadzu, Columbia, MD).

Chromatographic separation of peptides was accomplished on an Ultrasphere ODS column $(250 \times 4.6 \mathrm{~mm}$ I.D., $5 \mu \mathrm{m}$ particles diameter $)$ preceded by a pre-column $(45 \times 4.6 \mathrm{~mm}$ I.D. $)$ filled with the same material and both obtained from Beckman Instruments. A linear gradient system was employed for the separation of derivatized hormones consisting of $48-80 \%$ of solvent B $(0.1 \%$ TFA in acetonitrile-water, $3: 1)$ in solvent A ( $0.1 \%$ TFA in water) for $20 \mathrm{~min}$. The column temperature was $22{ }^{\circ} \mathrm{C}$ and the flow rate $1 \mathrm{~mL} / \mathrm{min}$. Fluorescence detection was carried out at $530 \mathrm{~nm}$ with excitation at $470 \mathrm{~nm}$. The two peptides were analyzed simultaneously in every sample and data expressed as pmol of peptide per tissue weight $(\mathrm{mg})$.

\section{Quantification of cortisol levels by radioimmunoassay}

Free cortisol was extracted from plasma samples by adding diethyl-ether to the samples, centrifuging the mix $(3000 \mathrm{rpm}$, $10 \mathrm{~min}, 4{ }^{\circ} \mathrm{C}$ ) and subsequently freezing it $\left(10 \mathrm{~min},-80^{\circ} \mathrm{C}\right)$ in order to separate the ether fraction (containing the free cortisol) from the aqueous one, which was then evaporated and the steroids were re-suspended in phosphate buffer. Cortisol concentrations were measured by radioimmunoassay, using a commercial antibody (Cortisol-32, ref. 20-CR50, Interchim/Fitzgerald, Montluçon, France) and a reactive marker ([1,2,6,7-3H] Cortisol, ref. TRK407-250 mCi, Amersham Biosciences, Piscataway, NJ, USA). Inter- and intra-assay variabilities were $5.7 \%$ and $5.2 \%$ respectively.

\section{Data analysis}

Variables conform to parametric parameters (normality and homogeneity of variances as assessed by Levene's test) and therefore no transformations were performed. A repeated measures ANOVA (repeated factor: brain macroareas with 7 levels, one for each area; independent factor: male status with 2 levels, dominant vs. subordinate status) was used to investigate the main effects and the interaction between brain area and social status on AVT and IT levels, followed by the Tukey post-hoc tests for unequal sample sizes to assess the effects of brain area and of social status per se. Although we have sampled 8 dominant and 8 subordinate males, sample sizes may vary across different brain areas because some samples were lost during different phases of processing. We have also removed one AVT data point from HB that was identified as an outlier (i.e. value over 3 standard deviations) and another from DE that failed to show an AVT peak. T-tests were used to compare AVT and IT levels for each brain area, as well as circulating cortisol levels, between dominant and subordinate males. Pearson correlations were used to assess the association between AVT and IT levels across different brain areas, and between pituitary AVT and circulating cortisol levels. All statistical analyses were performed using the software package STATISTICA v.10 (StatSoft, Inc., 2011).

\section{Results}

There is a significant main effect of brain area but not of social status on the brain concentrations of both AVT (repeated measures ANOVA brain area main effect: $\mathrm{F}_{6,24}=56,34, \mathrm{p}<0.0001$; social status main effect: $\mathrm{F}_{1,4}=2,81, \mathrm{p}=0.17$ ) and IT (repeated measures ANOVA, brain area main effect: $F_{6,30}=187, p<0.0001$; social status main effect: $\mathrm{F}_{1,5}=1,86, \mathrm{p}=0.23$ ). The post-hoc analyses reveal that AVT levels are significantly higher in the pituitary, followed by the olfactory bulbs that also have significantly higher levels than the rest of the brain areas (see Fig. 1A), and that IT levels are significantly higher in the pituitary than in any of the brain areas (see Fig. 1B). There is also a significant interaction between the 2 main factors (i.e. brain area and social status)
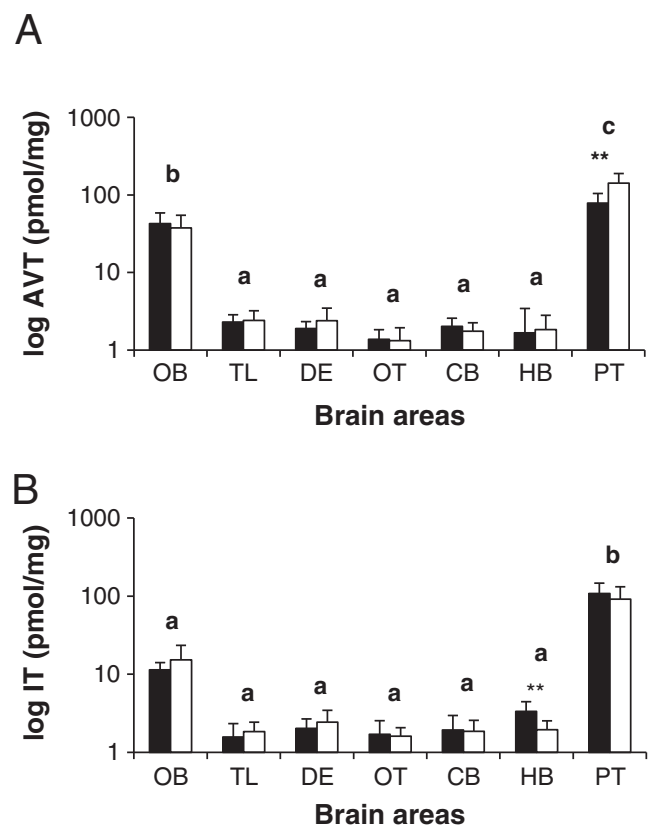

Fig. 1. Arginine vasotocin (A) and isotocin (B) brain area levels (Mean + SD) in dominants (filled bars) and subordinates (open bars) of 0 . mossambicus. Brain areas (sample size for dominants, sample size for subordinates): OB-olfactory bulbs $(4,4)$; TL-telencephalon $(8,8)$; DE-diencephalon $(6,8$ for AVT; 7,8 for IT); OT-optic tectum $(7,8)$; CB-cerebellum $(8,8)$; HB-hindbrain $(8,7$ for AVT; 8,8 for IT) and PT-pituitary $(8$, 6). Significant correlations are marked with ${ }^{* *}$ for $\mathrm{p}<0.01$. 
Table 1

Correlations of AVT (below the diagonal) and IT (above the diagonal) levels between the different brain areas (olfactory bulbs, OB; telencephalon, TL; optic tectum, OT; cerebellum, CB; hindbrain, HB; diencephalon, DE) and pituitary gland (PT); sample sizes are given between brackets; significant correlations are highlighted in bold marked with ${ }^{*}$ for $\mathrm{p}<0.05$ and with ${ }^{* *}$ for $\mathrm{p}<0.01$.

\begin{tabular}{llllllll}
\hline & OB & TL & OT & CB & HB & DE & PT \\
\hline OB & - & 0.548 & -0.177 & 0.004 & -0.396 & -0.129 & 0.084 \\
& & $(8)$ & $(8)$ & $(8)$ & $(8)$ & $(8)$ & $(7)$ \\
TL & 0.500 & - & -0.044 & 0.154 & -0.174 & 0.306 & $-\mathbf{0 . 7 0 3 * *}$ \\
& $(8)$ & & $(15)$ & $(16)$ & $(16)$ & $(15)$ & $(\mathbf{1 4})$ \\
OT & -0.423 & 0.058 & - & -0.132 & 0.430 & 0.239 & -0.107 \\
& $(8)$ & $(15)$ & & $(15)$ & $(15)$ & $(15)$ & $(13)$ \\
CB & -0.229 & 0.338 & $\mathbf{0 . 5 3 2}$ & - & $-\mathbf{0 . 5 7 3}$ & 0.400 & -0.449 \\
& $(8)$ & $(16)$ & $(\mathbf{1 5})$ & & $(\mathbf{1 6})$ & $(15)$ & $(14)$ \\
HB & 0.319 & -0.154 & 0.183 & -0.021 & - & -0.391 & 0.399 \\
& $(8)$ & $(15)$ & $(14)$ & $(15)$ & & $(15)$ & $(14)$ \\
DE & 0.177 & 0.453 & 0.044 & 0.293 & 0.247 & - & -0.252 \\
& $(7)$ & $(14)$ & $(14)$ & $(14)$ & $(13)$ & & $(13)$ \\
PT & -0.033 & -0.121 & 0.466 & -0.182 & 0.432 & 0.340 & - \\
& $(7)$ & $(14)$ & $(13)$ & $(14)$ & $(14)$ & $(12)$ & \\
\hline
\end{tabular}

both for AVT $\left(\mathrm{F}_{6,24}=3,60, \mathrm{p}<0.05\right)$ and for IT $\left(\mathrm{F}_{6,30}=2,84, \mathrm{p}<0.05\right)$, suggesting that the effect of social status on nonapeptide levels is not homogeneous across all brain areas. Contrast analysis of AVT and IT levels of an area by area basis revealed that AVT levels are significantly higher in subordinate males in the pituitary gland ( $t$-test: $T=-3.219$, $\mathrm{p}<0.01$ ), and that IT levels are significantly higher in dominants in the rombencephalon ( $t$-test: $\mathrm{T}=-3.146, \mathrm{p}<0.01$ ).

Correlations in nonapeptide levels between the pituitary and different brain areas are mostly absent (Table 1). Only IT levels in the telencephalon are negatively correlated with IT pituitary levels, suggesting that overall the peripheral and the central secretions of these nonapeptides are independent from each other. AVT and IT levels were not correlated neither within each brain area (OB: $r=-0.059, \mathrm{~N}=8, \mathrm{p}=0.89$;TL: $\mathrm{r}=-0.304, \mathrm{~N}=16, \mathrm{p}=0.253 ; \mathrm{DE}: \mathrm{r}=-0.158, \mathrm{~N}=14, \mathrm{p}=0.589$; OT: $r=0.436, N=15, p=0.104 ; C B: r=-0.407, N=16, p=0.117$; RB: $r=0.336, N=15, p=0.221)$ nor in the pituitary $(r=-0.1273$, $\mathrm{N}=14, \mathrm{p}=0.664$ )

There are no differences in cortisol levels between dominant and subordinate males (mean \pm S.E.M.: dominants $=29.4 \pm 5.7 \mathrm{ng} / \mathrm{mL}$, subordinates $=43.3 \pm 7.4 \mathrm{ng} / \mathrm{mL} ; \quad t$-test: $\mathrm{t}=-1.50, \quad$ d.f. $=14$, $\mathrm{p}=0.157)$ and there are no significant correlations between plasma cortisol levels and AVT or IT peptide levels in the pituitary (AVT, $r=0.245, n=14, p=0.40 ;$ IT, $r=0.12, n=14, p=0.68$ ).

Dominant males store more urine than subordinates ( $t$-test: $\mathrm{T}=3.453, \mathrm{p}<0.01$; Fig. 2).

\section{Discussion}

The results presented here indicate that AVT and IT levels are much higher in the pituitary gland than in any of the major brain areas which support the main role of these nonapeptides as peripheral

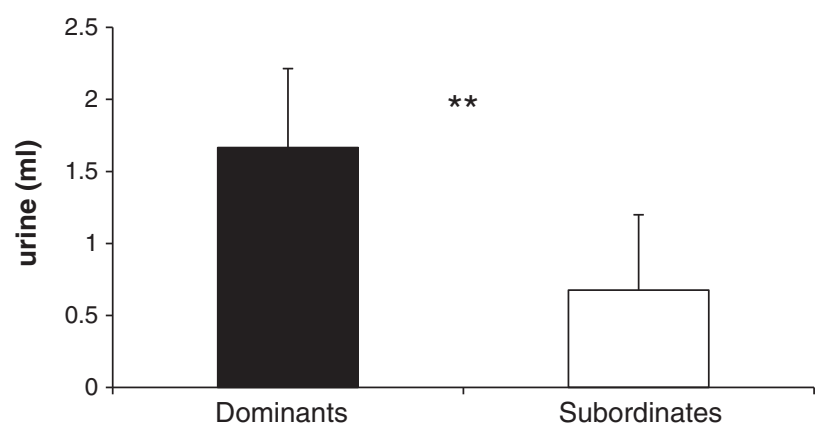

Fig. 2. Volume of urine $($ Mean $+\mathrm{SD})$ stored by dominants $(\mathrm{N}=8)$ and subordinates $(\mathrm{N}=8)$ males of 0 . mossambicus. ${ }^{* *} \mathrm{p}<0.01$. hormones that promote integrated physiological changes. However, both AVT and IT are also present in quantifiable levels in all major brain areas, therefore confirming the ubiquitous presence of these neuropeptides in the teleost fish brain as suggested by previous ICC and ISH studies (Dewan and Tricas, 2011; Dewan et al., 2008, 2011; Goodson and Bass, 2001; Goodson et al., 2003; Holmqvist and Ekstrom, 1995; Saito et al., 2004; Thompson and Walton, 2009) and supporting their role as central neuromodulators (Goodson, 2008; Goodson and Thompson, 2010). In this respect it is particularly interesting the finding of significantly high levels of AVT in the olfactory bulbs, which was by far the brain region with the highest concentration of this peptide.

In rodents AVP plays an important role in the modulation of olfactory-based social recognition, an effect mainly regulated by the lateral septum (for a comprehensive review see McEwen, 2004). More recently, new populations of AVP neurons have been identified both intrinsically in the olfactory bulbs and in the anterior olfactory nucleus of the rat cortex (Tobin et al., 2010; Wacker et al., 2010), and the expression of AVP receptors has also been described for these two regions (e.g. V1a receptors in granular cells and V1b receptors in mitral cells of the main olfactory bulbs; see Wacker et al., 2011 for a review). Finally, the role of AVP modulation in the olfactory bulbs is confirmed by the negative effect on social memory retention induced by the infusion of a V1 receptor antagonist or by genetically ablating AVP neurons in the main olfactory bulbs (Tobin et al., 2010). Thus, AVP acting at the level of the olfactory bulbs facilitates short-term social odor memory in rodents.

In fish olfaction also plays a major role in intra-specific communication (Stacey and Sorensen, 2002), including social recognition (Gerlach et al., 2008). Although an AVT neuronal population has never been described in the olfactory bulbs of teleosts, V1a receptors have been identified in this area (Kline et al., 2011), which together with the high AVT peptide levels reported here, suggest a role for AVT in the processing of olfactory stimuli in fish. The Mozambique tilapia may prove to be an excellent model species for investigating the AVT modulation of olfactory-based social communication in fish, since urine-born compounds are actively used both in agonistic male-male interactions and during courtship in this species (Almeida et al., 2005; Barata et al., 2007; Frade et al., 2002). Males store urine in the bladder and, by controlling a sphincter in the urogenital papilla, are able to release it in a pulsating way. The rate of urination has been shown to be higher in the presence of a pre-ovulated female in contrast of a post ovulated female, demonstrating that males are able to assed the reproductive status of the female and alter their behavior accordingly (Almeida et al., 2005). Males also release short duration (ca. $1 \mathrm{~s}$ ) pulses of urine during the assessment phase of male-male aggressive interactions, but only dominants keep on releasing urine after a clear dominance relationship is established (Barata et al., 2007). Moreover, urine from dominant males has a higher olfactory potency (as measured by an electrolfactogram assay) than that of subordinates (Barata et al., 2007). Thus, the high concentrations of AVT in the olfactory bulbs of tilapia might be related with olfactory memories that may provide information on female reproductive status and on male social status.

The fact that urine is stored and used as a vehicle for chemical communication in tilapia also raises the hypothesis that AVT may be coupling the processing of chemical information at the level of the CNS with the production of the chemical signal through its antidiuretic effects in the kidney. In contrast to its predominant tubular effects in mammals, the antidiuretic effect of AVT in fish is achieved by decreasing glomerular filtration rates which results in an increase in water reabsorption and a decrease in urine flow (Amer and Brown, 1995; Konno et al., 2010; Warne et al., 2002). As a first investigation of this hypothesis we collected data on volumes of urine stored by dominant and subordinate males. In accordance to our hypothesis, dominant males that have lower pituitary concentrations of AVT than subordinates, suggesting also lower levels of peripheral AVT (assuming is released shortly after it is produced), exhibited higher volumes of stored urine. This result 
confirms previously published data on differential urine storage by dominant vs. subordinate males of this species (Barata et al., 2007).

At the brain level differences between dominant and subordinate males were only found for IT levels in the hindbrain. Actions of nonapeptides in the hindbrain have been reported both in relation to autonomic output and in relation to motor control centers involved in species-specific behaviors. For example, in goldfish the basic approach-withdrawal tendency towards a conspecific is regulated by AVT (negative effect) and IT (positive effect) (Thompson and Walton, 2004). Recently, the effect of AVT has been shown to be located in the hindbrain with infusions at the level of the 4th ventricle being more effective than those at the level of the 3rd ventricle, and to rely on a peripheral feedback mechanism that involves an interaction between AVT and substance $\mathrm{P}$ neurons in the rhombencephalon (Thompson et al., 2008). Although, no data is yet available for the effects of IT on the hindbrain it is possible that its behavioral effects described above are also acting at this level, in which case our results may suggest a higher tendency of dominant males to engage in social interactions. It could also be argued that the differences observed between dominants and subordinates on IT hindbrain levels are due to differences in activity levels between these social phenotypes. However, previous studies on this species have shown no significant differences in activity levels between individuals of different social status (Oliveira, 1995).

At the level of the pituitary subordinate males had higher AVT levels than dominants, which could be interpreted as a potential effect of social stress on the activation of the hypophysial AVT secretion. However, and despite the established role of AVT in the stress response by acting synergetically with corticotrophin releasing hormone $(\mathrm{CRH})$ as an adrenocorticotropin (ACTH) secretagogue in the hypothalamic pituitary inter-renal (HPI) axis (Baker et al., 1996), we found no significant correlation between AVT pituitary levels and circulating cortisol concentrations. We also found no differences in cortisol levels between dominant and subordinate males. Given the fact that the males used in this study were taken from stable social groups with their status being stable for over 5 to 8 weeks, it is possible that the HPA axis has habituated to social challenges and that hormone levels have became uncoupled from social behavior. Indeed, the observed higher glucocorticoid levels observed in subordinate individuals in experimental paradigms is in many cases an acute effect that is not detected when assessing the relationship between social status and basal glucocorticoid levels in stable social groups (Abbott et al., 2003; Creel, 2001). A dissociation between AVT and CRH and cortisol responses to stress has already been reported for other fish species (e.g. Backström et al., 2011), and so it could be postulated that, contrary to the CRH-cortisol system, AVT maintains a heightened response to chronic social stress in subordinate fish. However, other studies have also demonstrated a habituation of the parvocellular AVT response to chronic stress (Gilchriest et al., 2000). Thus, further research is needed to clarify this point.

The lack of correlations between pituitary and (most) brain region levels of each nonapeptide (only exception is for IT in the telencephalon) suggests an independent secretion of each of these peptides through their hypophysial and extrahypothalamic projections. These results contrast with structural data that suggests a coupling of the two systems. Two mechanisms have been described that suggest the coordinated control of neurohypophysial and central outputs of the nonapeptidergic systems. First, both AVT and IT neurons cluster together forming celltype-specific networks with synchronized electric activity (Cumming et al., 1982; Saito and Urano, 2001; Saito et al., 2004). Second, a study in rainbow trout, where projections from single cells were stained with biocytin, revealed that single AVT and IT cells have multiple projections both towards the pituitary and the extrahypothalamic regions (Saito et al., 2004). The apparent contradiction between our results and the abovementioned evidence for a coupling between the central and peripheral nonapeptide system, can be solved if one considers that the mechanism of dendritic neuropeptide release recently described for rodents is also present in fish. In rats, magnocellular neurons can release significant amounts of vasopressin or oxytocin from their dendrites as well as from their axons, but not necessarily under the same conditions (Ludwig and Leng, 2006). This might be happening in fish as well and could explain the lack of correlation between central and peripheral levels.

There were also no correlations between AVT and IT neither for each of the brain regions nor for the pituitary, suggesting an independent secretion of these two peptides. These results are in accordance with previously published work. AVT and IT diurnal variation in Sea bream (Sparus aurata) and juvenile Atlantic salmon (Salmo salar), and the seasonal fluctuations in three-spined sticklebacks (Gasterosteus aculeatus) are independent from each other suggesting that each peptide plays a different role in a circadian time-keeping system and an endocrine calendar in fish (Gozdowska et al., 2006). Moreover, in rainbow trout a lack of correlation of periodic $\mathrm{Ca}^{2+}$ pulses between AVT and IT neurons also suggests that these two neuronal groups function independently from each other (Saito and Urano, 2001).

In summary, the results presented here highlight the importance of collecting information on peptide levels to complement the structural and electrophysiological information when investigating the role of nonapeptides on social behavior.

\section{Acknowledgments}

This study was funded by the research grants PTDC/PSI/71811/ 2006 and PTDC/MAR/72117/2006 from Fundação para a Ciência e a Tecnologia (FCT, Portugal; grant holder: R. Oliveira), the European Commission FEDER Program, and the FCT Pluriannual Program (R\&D unit MAR-LVT-Lisboa-331; grant holder: R. Oliveira). During this project O. Almeida was being supported by a PhD fellowship from FCT (SFRH/ $\mathrm{BD} / 37187 / 2007)$, and received a travel grant from the COST Action 867 (STSM-867-3002) of the European Science Foundation for a short term visit to the lab of Prof. Kulczykowska in Poland. Peptide analyses were supported by the research grant 568/N-COST from Institute of Oceanology PAS (grant holder: E. Kulczykowska).

\section{References}

Abbott, D.H., Keverne, E.B., Bercovitch, F.B., Shively, C.A., Mendoza, S.P., Saltzman, W., Snowdon, C.T., Ziegler, T.E., Banjevic, M., Garland Jr. T., Sapolsky, R.M., 2003. Are subordinates always stressed? A comparative analysis of rank differences in cortisol levels among primates. Horm. Behav. 43, 67-82.

Almeida, O.G., Miranda, A., Frade, P., Hubbard, P.C., Barata, E.N., Canário, A.V.M., 2005. Urine as a social signal in the Mozambique tilapia (Oreochromis mossambicus) Chem. Senses 30, 309-310.

Amer, S., Brown, J.A., 1995. Glomerular actions of arginine vasotocin in the in situ perfused trout kidney. Am. J. Physiol. 269 (4 Pt 2), R775-R780.

Backström, T., Schjolden, J., Øverli, Ø., Thörnqvist, P.O., Winberg, S., 2011. Stress effects on AVT and CRF systems in two strains of rainbow trout (Oncorhynchus mykiss) divergent in stress responsiveness. Horm. Behav. 59, 180-186.

Baerends, G.P., Baerends van Roon, J.M., 1950. An introduction to the ethology of cichlid fishes. Behaviour Suppl. 1, 1-242.

Baker, B.I., Bird, D.J., Buckingham, J.C., 1996. In the trout, CRH and AVT synergize to stimulate ACTH release. Regul. Pept. 67, 207-210.

Balment, R.J., Warne, J.M., Tierney, M., Hazon, N., 1993. Arginine vasotocin and fish osmoregulation. Fish Physiol. Biochem. 11, 189-194.

Balment, R.J., Lu, W., Weybourne, E., Warne, J.M., 2006. Arginine vasotocin a key hormone in Wsh physiology and behaviour: a review with insights from mammalian models. Gen. Comp. Endocrinol. 147, 9-16.

Barata, E.N., Hubbard, P.C., Almeida, O.G., Miranda, A., Canário, A.V.M., 2007. Male urine signals social rank in Mozambique tilapia (Oreochromis mossambicus, Peters 1852). BMC Biol. 5, 54.

Bastian, J., Schniederjan, S., Nguyenkim, J., 2001. Arginine vasotocin modulates a sexually dimorphic communication behavior in the weakly electric fish Apteronotus leptorhynchus. J. Exp. Biol. 204, 1909-1923.

Bruton, M.N., Boltt, R.E., 1975. Aspects of the biology of Tilapia mossambica Peters (Pisces: Cichlidae) in a natural freshwater lake (Lake Sibaya, South Africa). J. Fish Biol. 7 423-446.

Carneiro, L.A., Oliveira, R.F., Canário, A.V.M., Grober, M.S., 2003. The effect of arginine vasotocin on courtship behaviour in a blenniid fish with alternative reproductive tactics. Fish Physiol. Biochem. 28, 241-243.

Creel, S., 2001. Social dominance and stress hormones. Trends Ecol. Evol. 16, 491-497.

Cumming, R., Reaves Jr., T.A., Hayward, J.N., 1982. Ultrastructural immunocytochemical characterization of isotocin, vasotocin and neurophysin neurons in the magnocellular preoptic nucleus of the goldfish. Cell Tissue Res. 223, 685-694. 
Dewan, A.K., Tricas, T.C., 2011. Arginine vasotocin neuronal phenotypes and their relationship to aggressive behavior in the territorial monogamous multiband butterflyfish, Chaetodon multicinctus. Brain Res. 1401, 74-84.

Dewan, A.K., Maruska, K.P., Tricas, T.C., 2008. Arginine vasotocin neuronal phenotypes among congeneric territorial and shoaling reef butterflyfishes: species, sex and reproductive season comparisons. J. Neuroendocrinol. 20, 1382-1394.

Dewan, A.K., Ramey, M.L., Tricas, T.C., 2011. Arginine vasotocin neuronal phenotypes, telencephalic fiber varicosities, and social behavior in butterflyfishes (Chaetodontidae): potential similarities to birds and mammals. Horm. Behav. 59, 56-66.

Foo, J.T.W., Lam, T.J., 1993. Serum cortisol response to handling stress and the effect of cortisol implantation on testosterone level in the tilapia, Oreochromis mossambicus. Aquaculture 115, 145-158.

Frade, P., Hubbard, P.C., Barata, E.N., Canário, A.V.M., 2002. Olfactory sensitivity of the Mozambique tilapia to conspecific odours. J. Fish Biol. 61, 1239-1254.

Fryer, G., Iles, T.D., 1972. The Cichlid Fishes of the Great Lakes of Africa-Their Biology and Evolution. Oliver and Boyd, Edinburgh.

Gerlach, G., Hodgins-Davis, A., Avolio, C., Schunter, C., 2008. Kin recognition in zebrafish: a 24-hour window for olfactory imprinting. Proc. Biol. Sci. 275, 2165-2170.

Gilchriest, B.J., Tipping, D.R., Hake, L., Levy, A., Baker, B.I., 2000. The effects of acute and chronic stresses on vasotocin gene transcripts in the brain of the rainbow trout (Oncorhynchus mykiss). J. Neuroendocrinol. 12, 795-801.

Goodson, J.L., 2008. Nonapeptides and the evolutionary patterning of sociality. Prog. Brain Res. 170, 3-15.

Goodson, J.L., Bass, A.H., 2000a. Forebrain peptides modulate sexually polymorphic vocal circuitry. Nature 403, 769-772.

Goodson, J.L., Bass, A.H., 2000b. Vasotocin innervation and modulation of vocal-acoustic circuitry in the teleost Porichthys notatus. J. Comp. Neurol. 422, 363-379.

Goodson, J.L., Bass, A.H., 2001. Social behavior functions and related anatomical characteristics of vasotocin/ vasopressin systems in vertebrates. Brain Res. Rev. 35, 246-265.

Goodson, J.L., Thompson, R.R., 2010. Nonapeptide mechanisms of social cognition, behavior and species-specific social systems. Curr. Opin. Neurobiol. 20, 784-794.

Goodson, J.L., Evans, A.K., Bass, A.H., 2003. Putative isotocin distributions in sonic fish: relation to vasotocin and vocal-acoustic circuitry. J. Comp. Neurol. 462, 1-14.

Gozdowska, M., Kulczykowska, E., 2004. Determination of arginine-vasotocin and isotocin in fish plasma with solid-phase extraction and fluorescence derivatization followed by high-performance liquid chromatography. J. Chromatogr. B 807, 229-233.

Gozdowska, M., Kleszczyńska, A., Sokołowska, E., Kulczykowska, E., 2006. Arginine vasotocin (AVT) and isotocin (IT) in fish brain: diurnal and seasonal variations. Comp. Biochem. Physiol. B Biochem. Mol. Biol. 143, 330-334.

Greenwood, A.K., Wark, A.R., Fernald, R.D., Hofmann, H.A., 2008. Expression of arginine vasotocin in distinct preoptic regions is associated with dominant and subordinate behaviour in an African cichlid fish. Proc. Biol. Sci. 275, 2393-2402.

Hausmann, H., Meyerhof, W., Zwiers, H., Lederis, K., Richter, D., 1995. Teleost isotocin receptor: structure, functional expression, mRNA distribution and phylogeny. FEBS Lett. 370, 227-230

Holmqvist, B.I., Ekstrom, P., 1995. Hypophysiotrophic systems in the brain of the Atlantic salmon. Neuronal innervation of the pituitary and the origin of pituitary dopamine and nonapeptides identified by means of combined carbocyanine tract tracing and immunocytochemistry. J. Chem. Neuroanat. 8, 125-145.

Kleszczyńska, A., Vargas-Chacoff, L., Gozdowska, M., Kalamarz, H., Martínez-Rodríguez, G., Mancera, J.M., Kulczykowska, E., 2006. Arginine vasotocin, isotocin and melatonin responses following acclimation of gilthead sea bream (Sparus aurata) to different environmental salinities. Comp. Biochem. Physiol. A Mol. Integr. Physiol. 145, 268-273.

Kleszczyńska, A., Dumont, E., Cornelis, R., Gozdowska, M., Kulczykowska, E., Sandra, P. 2007. Determination of the neuropeptides arginine vasotocin and isotocin in brains of three-spined sticklebacks (Gasterosteus aculeatus) by off-line solid phase extraction-liquid chromatography-electrospray tandem mass spectrometry. J. Chromatogr. A 1150, 290-294.

Kline, R.J., O'Connell, L.A., Hofmann, H.A., Holt, G.J., Khan, I.A., 2011. The distribution of an AVT V1a receptor in the brain of a sex changing fish, Epinephelus adscensionis. J. Chem. Neuroanat. 42, 72-88.

Konno, N., Hyodo, S., Yamaguchi, Y., Matsuda, K., Uchiyama, M., 2010. Vasotocin/V2-type receptor/aquaporin axis exists in African lungfish kidney but is functional only in terrestrial condition. Endocrinology 151, 1089-1096.

Kulczykowska, E., 2007. Arginine vasotocin and isotocin: towards their role in fish osmoregulation. In: Baldisserotto, B., Mancero Romero, J.M., Kapoor, B.G. (Eds.), Fish Osmoregulation. Science Publisher, Enfield, N.H, pp. 151-176.

Larson, E.T., O'Malley, D.M., Melloni Jr., R.H., 2006. Aggression and vasotocin are associated with dominant-subordinate relationships in zebrafish. Behav. Brain Res. 167, 94-102.

Lema, S.C., 2010. Identification of multiple vasotocin receptor cDNAs in teleost fish: sequences, phylogenetic analysis, sites of expression, and regulation in the hypothalamus and gill in response to hyperosmotic challenge. Mol. Cell. Endocrinol. 321, 215-230.

Lema, S.C., Nevitt, G.A., 2004. Exogenous vasotocin alters aggression during agonistic exchanges in male Amargosa River pupfish (Cyprinodon nevadensis amargosae). Horm. Behav. 46, 628-637.
Lema, S.C., Wagstaff, L.J., Gardner, N.M., 2010. Diurnal rhythms of behavior and brain mRNA expression for argininevasotocin, isotocin, and their receptors in wild Amargosa pupfish (Cyprinodon nevadensis amargosae). Mar. Freshwater Behav. Physiol. 43, 257-281.

Ludwig, M., Leng, G., 2006. Dendritic peptide release and peptide-dependent behaviours. Nat. Rev. Neurosci. 7, 126-136.

McEwen, B.B., 2004. The roles of vasopressin and oxytocin in memory processing. Adv. Pharmacol. 50, 1-740.

Neil, E.H., 1964. An analysis of colour changes and social behaviour of Tilapia mossambica. Univ. Calif. Publ. Zool. 75, 1-58.

Oliveira, R.F. 1995. Etologia social e endocrinologia comportamental da tilapia Oreochromis mossambicus (Teleostei, Cichlidae). Ph.D. Thesis, University of Lisbon, Lisbon.

Oliveira, R.F. 2006. Neuroendocrine mechanisms of alternative reproductive tactics in fish. In: K.A. Sloman, R.W. Wilson, S. Balshine (Guest Editors; W.S. Hoar, D.J. Randall, A.P. Farrell, Series editors), Fish Physiology, vol. 24: Behaviour: Interactions with Physiology. Elsevier, New York.

Oliveira, R.F., Almada, V.C., 1996a. Dominance hierarchies and social structure in captive groups of the Mozambique tilapia Oreochromis mossambicus (Teleostei: Cichlidae). Ethol. Ecol. Evol. 8, 39-55.

Oliveira, R.F., Almada, V.C., 1996b. On the (In)stability of dominance hierarchies in the cichlid fish Oreochromis mossambicus. Aggress. Behav. 22, 37-45.

Oliveira, R.F., Almada, V.C., 1998. Mating tactics and male-male courtship in the lek-breeding cichlid Oreochromis mossambicus. J. Fish Biol. 52, 1115-1129.

Oliveira, R.F., Almada, V.C., Canario, A.V.M., 1996. Social modulation of sex steroid concentrations in the urine of male cichlid fish Oreochromis mossambicus. Horm. Behav. 30, 2-12.

Pickford, G.E., Strecker, E.L., 1977. The spawning reflex response of the killifish, Fundulus heteroclitus: isotocin is relatively inactive in comparison with arginine vasotocin. Gen. Comp. Endocrinol. 32, 132-137.

Saito, D., Urano, A., 2001. Synchronized periodic Ca2 + pulses define neurosecretory activities in magnocellular vasotocin and isotocin neurons. J. Neurosci. 21, 178 .

Saito, D., Komatsuda, M., Urano, A., 2004. Functional organization of preoptic vasotocin and isotocin neurons in the brain of rainbow trout: central and neurohypophysial projections of single neurons. Neuroscience 124, 973-984.

Salek, S.J., Sullivan, C.V., Godwin, J., 2002. Arginine vasotocin effects on courtship behavior in male white perch (Morone americana). Behav. Brain Res. 133, 177-183.

Santangelo, N., Bass, A.H., 2006. New insights into neuropeptide modulation of aggression: field studies of arginine vasotocin in a territorial tropical damselfish. Proc. R. Soc. Lond. 273, 3085-3092.

Semsar, K., Kandel, F.L., Godwin, J., 2001. Manipulations of the AVT system shift social status and related courtship and aggressive behavior in the bluehead wrasse. Horm. Behav. 40, 21-31.

Stacey, N.E., Sorensen, P.W., 2002. Hormonal sex pheromones in fish. In: Pfaff, D.W., Arnold, A.P., Etgen, A.M., Fahrbach, S.E., Rubin, R.T. (Eds.), Hormones, Brain, and Behavior. Editors Academic Press, New York, pp. 375-434.

StatSoft, Inc., 2011. STATISTICA (data analysis software system), version 10. www. statsoft.com 2011 .

Taborsky, M., 1997. Bourgeois and parasitic tactics: do we need collective, functional terms for alternative reproductive behaviours? Behav. Ecol. Sociobiol. 41, 361-362.

Thompson, R.R., Walton, J.C., 2004. Peptide effects on social behavior: effects of vasotocin and isotocin on social approach behavior in male goldfish (Carassius auratus). Behav. Neurosci. 118, 620-626.

Thompson, R.R., Walton, J.C., 2009. Vasotocin immunoreactivity in goldfish brains: characterizing primitive circuits associated with social regulation. Brain Behav. Evol. 73, 153-164.

Thompson, R.R., Walton, J.C., Bhalla, R. George, K.C., Beth, E.H., 2008. A primitive social circuit: vasotocin-substance $P$ interactions modulate social behavior through a peripheral feedback mechanism in goldfish. Eur. J. Neurosci. 27 (9), 2285-2293.

Tobin, V.A., Hashimoto, H., Wacker, D.W., Takayanagi, Y., Langnaese, K., Caquineau, C., Noack, J., Landgraf, R., Onaka, T., Leng, G., Meddle, S.L., Engelmann, M., Ludwig, M., 2010. An intrinsic vasopressin system in the olfactory bulb is involved in social recognition. Nature 464, 413-417.

Wacker, D.W., Tobin, V.A., Noack, J., Bishop, V.R., Duszkiewicz, A.J., Engelmann, M., Meddle, S.L., Ludwig, M., 2010. Expression of early growth response protein 1 in vasopressin neurones of the rat anterior olfactory nucleus following social odour exposure. J. Physiol. 588, 4705-4717.

Wacker, D.W., Engelmann, M., Tobin, V.A., Meddle, S.L., Ludwig, M., 2011. Vasopressin and social odor processing in the olfactory bulb and anterior olfactory nucleus. Ann. N. Y. Acad. Sci. 1220, 106-116.

Warne, J.M., Harding, K.E., Balment, R.J., 2002. Neurohypophysial hormones and renal function in fish and mammals. Comp. Biochem. Physiol. B Biochem. Mol. Biol. 132, 231-237.

Wullimann, M.F., Mueller, T., 2004. Teleostean and mammalian forebrains contrasted: evidence from genes to behavior. J. Comp. Neurol. 475, 143-162. 